\title{
A compendium of causative agents of occupational asthma
}

\author{
Xaver Baur
}

\begin{abstract}
Objective: The objective is to provide an evidence-based compendium of allergenic and irritant agents that are known to cause occupational asthma in order to improve diagnostics and disease management.

Methods: Two previously published reviews from our group utilized database searches to identify studies which were then rated according to the Scottish Intercollegiate Guideline Network (SIGN) grading system. The evidence level for each causative agent or worksite was graded using the Royal College of General Practitioners (RCGP) three-star system.

Results: Approximately 3,000 relevant papers were identified, which covered 372 different causes of allergic and 184 different causes of irritant occupational asthma. The highest level achieved using the SIGN grading system was $2++$, indicating a high quality study with a very low risk of confounding or bias and a high probability of a causal relationship. Using the modified RCGP three-star grading system, the strongest evidence of association with an individual agent or worksite ('***') was found for exposure to laboratory animals. Associations with moderate

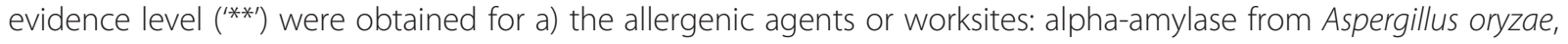
various enzymes from Bacillus subtilis, papain, bakeries, western red cedar, latex, psyllium, storage mites, rat, carmine, egg proteins, Atlantic salmon, fishmeal, Norway lobster, prawn, snow crab, seafood, trout and turbot, reactive dyes, b) the irritant agents or worksites: benzene-1,2,4-tricarboxylic acid, 1,2- anhydride [trimellitic anhydride], chlorine, cobalt, cement, environmental tobacco smoke, grain, welding fumes, construction work, swine confinement, World Trade Center disaster 2001, and c) agents or worksites causing allergic as well as irritant occupational asthma, included farming, poultry confinement, various isocyanates and platinum salts. A low evidence level (RCGP) was obtained for 84 agents or worksites (42 from each group), providing a total of 141 conditions with a low, moderate or strong evidence level.
\end{abstract}

Conclusion: This work comprises the largest compendium and evaluation of agents and worksites causing allergic or irritant occupational asthma from the literature assessed in an evidence-based manner.

\section{Introduction}

Occupational asthma is a disease characterized by variable airflow limitation and/or hyper-responsiveness associated with inflammation which is attributable to causes and conditions in a particular occupational environment and not to stimuli encountered outside the workplace [1]. Occupational asthma involves IgE-mediated asthma after a latency period, irritant asthma with or without a latency period, including reactive airways dysfunction syndrome (RADS), resulting from high exposure, and asthma due to specific occupational agents with

Correspondence: xaver.baur@charite.de

Institute for Occupational Medicine, Charité University Medicine Berlin and EOM Society, Berlin, Germany unknown pathomechanisms that may also show a latency period [2,3] (Figure 1). Occupational asthma needs to be differentiated from work-aggravated asthma, which is characterized by a worsening of pre-existing asthma or increase in airway resistance, asthma medications or frequency and/or severity of asthma attacks arising from causes and conditions attributable to a particular occupational environment and not to stimuli encountered outside the workplace. These workers have a concurrent history of asthma that was not induced by exposure in the workplace. Aggravation is typically due to an occupational irritant (e.g. non-sensitizing fumes) [4]. There are also workers with pre-existing asthma who, after a latent interval, have a worsening of their pre-existing 


\section{Occupational asthma (OA) (new onset WRA)

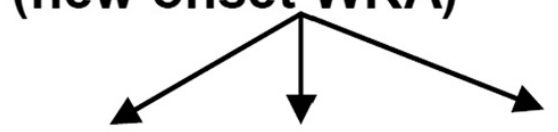 \\ $\lg \mathrm{E}$ media- ted OA \\ OA \\ due to specific occupational agents with unknown patho- mechanism}

Figure 1 Subgroups of occupational asthma.

non-occupational asthma after regular daily exposure to agents which cause IgE-mediated allergies. No detailed studies or valid statistics relevant to work-aggravated asthma are available. The current study focuses on the identification of causes of occupational asthma and is based on two recently published reviews, evaluating occupational allergens [5] and irritants [6] in an evidencebased manner.

\section{Methods}

Appropriate terms were used to search Medline via PubMed (www.ncbi.nlm.nih.gov/mesh). The combination of medical subject headings (MeSH) used were as follows

\section{Occupational asthma due to allergens}

("1"[PDAT] : "2011/08/01"[PDAT]) AND $((((()((((" S i g n s$ and Symptoms, Respiratory"[MeSH] OR "Occupational Diseases"[MeSH]) OR "Allergy and Immunology"[Majr]) OR "Respiratory Function Tests"[MeSH]) OR "Bronchial Hyperreactivity"[MeSH]) OR "Airway Obstruction"[MeSH]) OR "Respiratory Hypersensitivity"[MeSH]) OR "Lung Diseases, Obstructive"[MeSH]) OR "Asthma"[MeSH]) OR "Asthma"[Mesh]) OR "Occupational Exposure"[MeSH]) AND "ALLERGEN"[MeSH]) AND ("humans"[MeSH] AND (English[lang] OR French[lang] OR German[lang]) AND "adult"[MeSH])

\section{Occupational asthma due to irritants}

This procedure differed from the aforementioned with "Respiratory Hypersensitivity"[MeSH]), "ALLERGEN"[MeSH]) replaced by "Asthma/chemically induced"[MeSH], "Lung Diseases, Obstructive/"chemically induced"[MeSH], "Occupational Diseases/chemically induced"[MeSH].
The searches were completed and included publications up until August 2011 (allergens) and to the end of June 2012 (irritants).

References collated in seminal systematic reviews or overviews of causes of work-related asthma were also included and the results from both approaches were combined.

The occupational diseases statistics based either on statutory surveillance or registration systems: SWORD 1994-1997 [7-9], SHIELD 1993 [10], SORDSA 2001 [11], SENSOR [12] and Dokumentation der Berufskrankheiten 2007 (BK-DOK) [13], were also included.

A list of agents denoted as "may cause sensitization by inhalation" by the phrase H334 (until 2011 R42), and as "may cause respiratory irritation" by the phrase H 335 (until 2011 R37), respectively, according to regulations of the European Parliament [14] was also considered.

All studies were assessed for potential biases (selection, confounding, information bias), in particular the sources of bias and bias minimisation strategies in either the design or analysis phase, specific to each study design.

The methodological quality of each selected publication was assessed by an experienced reviewer and discussed with the senior physician of the occupational unit who independently assessed the publications, before rating each according to the modified Scottish Intercollegiate Guidelines Network (SIGN) classification [15]. The slightly extended RCGP (Royal College of General Practitioners 1995) three-star system was used to grade the evidence for each agent on the basis of all available publications. The three-star system considers quality and quantity of all studies as well as consistency of reported findings. Our extensions comprised: [ ] indicated down-grading due to lower quality of clinical investigations, i.e., due to missing objective parameters such as lung-function data; further, ${ }^{(*)}$ indicated up-grading from '-' due to at least 5 reported asthma cases without contradictory findings (see Table 1). For further methodological details of the selection criteria, data extraction and synthesis, quality assessment of individual studies and the full list of ratings for each publication, see $[5,6]$.

\section{Results}

\section{Overview (Table 2)}

The database search resulted in 2,315 potentially relevant publications referring to allergen-induced asthma and 863 referring to irritant-induced asthma. After exclusion of non-occupational cases, a total of 865 allergen-induced and 474 irritant-induced asthma studies remained. These publications refer to 372 individual allergenic and 184 irritant agents or worksites that were identified to cause occupational asthma, of which 36 were listed as both allergens and irritants, leaving a final total of 520 different causes of occupational asthma. For 78 allergens and 71 


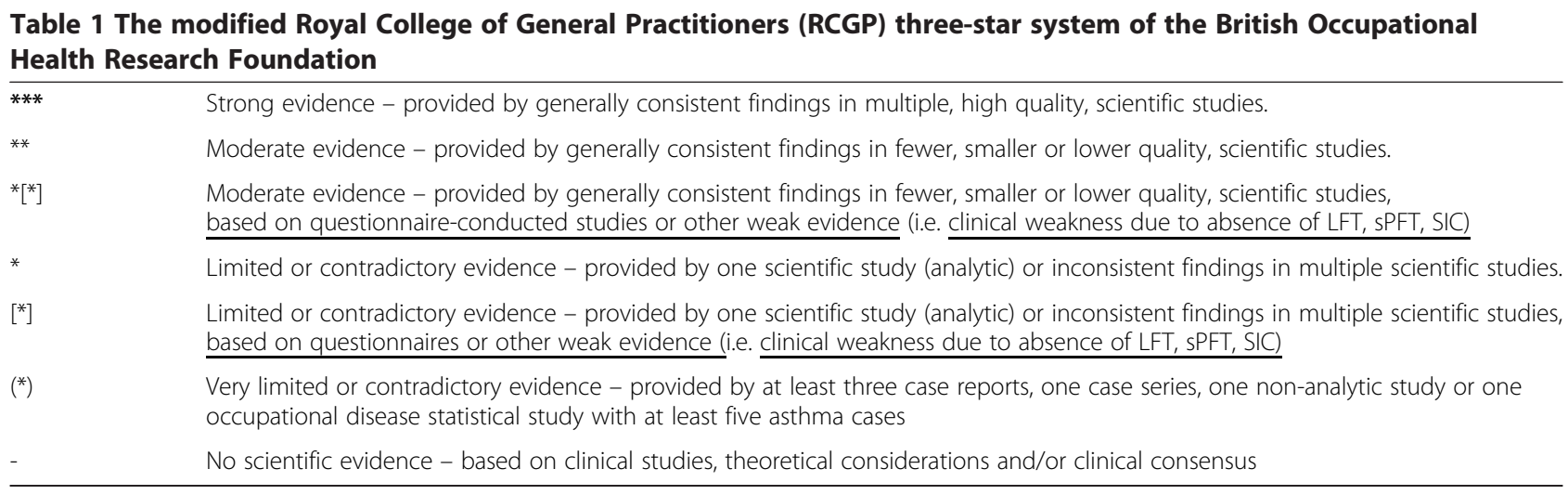

(BOHRF, [16]) Applied modifications are underlined.

irritants, (of which 12 were in both groups), an evidence level of at least ${ }^{(* \prime \prime)}$ in the RCGP grading system was found.

\section{Strength of evidence per agent or worksite (Table 3) Allergens}

Strong evidence, i.e. three stars “\%” was achieved from exposure to laboratory animals. For 18 agents or worksites, the strength of evidence corresponded to two stars ${ }^{\text {\%* }}$. Moderate evidence, provided by generally consistent findings in fewer, smaller or lower quality scientific studies with clinical weakness ${ }^{\prime *}\left[{ }^{*}\right]$ ' was found for 17 agents. Limited or contradictory evidence *;, was identified for 18 agents. For 24 agents, down-grading to '[*]' was necessary because of absent objective data.

The majority of agents were investigated in non-analytical studies. Thus, the strength of evidence ranged from very limited or contradictory evidence ' $\left({ }^{*}\right)$ ' (19 agents or worksites) to no scientific evidence '-' (275 agents or worksites).

\section{Irritants}

For 17 (mixed) agents or worksites, two stars "*\%' were achieved and none reached a higher level. Low to moderate scientific evidence, i.e. ' ${ }^{*}\left[{ }^{*}\right]$ ', was found for 12 agents. Limited or contradictory evidence. ${ }^{*}$ ' was identified for 39 agents or worksites and a further three agents were down-graded because of inadequate methodological

Table 2 Review of the literature on allergens or irritants causing occupational asthma

\begin{tabular}{lcc}
\hline Findings & Allergens & Irritants \\
\hline Potentially relevant publications and considered & 2,315 & 863 \\
$\begin{array}{l}\text { Publications which were found to be useful and } \\
\text { were included }\end{array}$ & 865 & 474 \\
$\begin{array}{l}\text { Different potential causative agent or workplaces } \\
\text { identified }\end{array}$ & 372 & 184 \\
$\begin{array}{l}\text { Evidence-based causative agents or workplaces* } \\
\text { P }\end{array}$ & 78 & 71 \\
\hline
\end{tabular}

*Overlap of 12 agents resulting of 137 different causative allergenic and/or irritant causative agents or workplaces. aspects. "Very limited or contradictory evidence" was obtained 29 times and no scientific evidence 94 times.

Interestingly, our literature search identified a group of 15 irritant agents or worksites that were found to cause occupational asthma and/or COPD, namely: ammonia, cement dust, chlorine, cleaning agents, mustard gas, diesel exhaust, environmental tobacco smoke, isocyanates, smoke from fires, sulfur dioxide, construction work, swine confinement, farming, foundry, metallurgic industry.

\section{Agents behaving as both allergen and irritant}

36 agents or worksites were found to cause allergic as well as irritant occupational asthma; for twelve of them evidence - mainly at a low level - was available (Table 4). With the exception of anhydrides and isocyanates there was no close relationship with the respective $\mathrm{H} 334$ and H335 phrases, respectively.

\section{Discussion}

As reported by various authors ([17-19]), about 15\% of adult asthma cases are caused by occupational agents, whether IgE-mediated or irritant occupational asthma or occupational asthma due to unknown pathomechanism. Irritant asthma may arise from high dose, moderate or even low dose exposure with the clinical pictures of RADS and not-so-sudden-onset irritant asthma. The latter, as well as occupational asthma of unknown pathomechanism, mostly show a latency period from the beginning of causative exposure until the appearance of symptoms, which makes these indistinguishable from allergic asthma [20].

Previous reports and reviews have accumulated narrative and experimental evidence for about 300 causative agents, which are often divided into high or low molecular weight groups ([21-28]). High molecular weight agents typically induce asthma through an IgE-mediated mechanism while the pathomechanism of low molecular weight agents is mostly airway irritation or unknown.

Quirce and Sastre recently summarised the newer causative agents published between 2009 and 2011 [22]. 
Table 3 Strength of evidence for occupational asthma-caused by allergens, irritants or worksites according to the modified RCGP three-star system

Evidence level Allergens /irritants: number Agent or worksite allergen Agent or worksite irritant

(modified RCGP

of agents or worksites

Agent or worksite irritant

three star grading)

[Synonym] (CAS) $1 / 0$

$18 / 12$
Co-exposure to various lab animals

Alpha-amylase from Aspergillus onyzae; various enzymes from Bacillus subtilis; papain; bakery (flour; amylase; storage mites); western red cedar; latex; Psyllium; farming (animals, cereal, hay, straw and storage mites); storage mites; rats; carmine; egg proteins; Atlantic salmon; fishmeal; Norway lobster; prawns; snow crabs; seafood; trout and turbot; reactive dyes; toluene diisocyanates (TDI); platinum salts;

Detergent enzymes, soybean (husks, flour); paprika; tea dust; tobacco; Aspergillus niger; cows; predatory mites; spider mites; opiates; methylene diphenyl diisocyanate (MDI), phthalic

anhydrides; various isocyanates

Eastern white cedar; various flowers; guar gum; poppy; rose (Rosa rugosa); senna; ispaghula husks; sunflower pollen; trypsin various woods (abies, chestnut, douglas, framire, mansonia, oak, obeche, walnut, white poplar); weeping fig; nonbiting midges; hexahydrophthalic anhydride; hexamethylene diisocyanate (HDI) methyl tetrahydrophthalic anhydride (MTHPA); persulfate salts; polyfunctional aziridine

Alternaria; bromelain from Ananas comosus; cellulase from Trichoderma viride; lactase from aspergillus; various enzymes: chrysanthemums; castor beans; madagascar jasmine; pine; flowers; budgerigar; flour moth; house dust mites; mouse; poultry; red soft corals; screw-worm fly; shrimp; various birds; cephalosporine; penicillins; phenylglycine; acid chloride; trimellitic anhydride

Aspergillus enzymes; cellulase from Trichoderma reesei; pancreatin proteolytic enzymes; asparagus; Boletus edulis; carnation; garlic dust; rye flour; gum arabic; iroko; various woods; African maple; black bat; mealworm; poultry mites; tetrachlorophtalic anhydride; chloramine T; chromium and nickel
Benzene-1,24-tricarboxylic acid; 1,2- anhydride [trimellitic anhydride] (552-30-7); Benzene-1,2,4-tricarboxylic acid; 1,2- anhydride [trimellitic anhydride] (552-30-7);
chlorine (7782-50-5): cobalt (7440-48-4); various isocyanates, isocyanurate (HDI, MDI, TDI), phenylmethane diisocyanate [MDI] (5873-54-1), toluene diisocyanate, $\mathrm{MDI}, \mathrm{TDI}$, phenylmethane diisocyanate [MDI] (5873-54-1), toluene diisocyan
TDI 2,4 (584-84-9),TDI 2,6: (91-08-7); platinum salts (7440-06-4); cement [78]; environmental tobacco smoke; grain [78]; welding fumes; construction work (dust, agent unspecified); farming, animals (pig, beef/veal, dairy, poultry); swine confinement; World Trade Center disaster 2001

Ceramic production [78]; phthalic anhydride (85-44-9); glutaraldehyde [glutaral] (11-30-8); sulfur dioxide (7446-09-5); cotton (dust; raw) CNT 750; potroom aluminum smelting; farming (various); foundry; smoke (fires, pyrolysis products); pesticides (unspecified); cleaning agents (unspecified): health care workers;

Acetic acid (64-19-7); sulfuric acid (7664-93-9); metacrylates; loctide (53858-53-0); aluminum salts [aluminum fluoride] (7724-18-1); aluminum sulfate: (10043-01-3); ammonia (7664-41-7); various anhydrides; tetrachlorophthalic anhydride (117-08-8); azobisformamide (123-77-3); cadmium (fumes) (7440-43-9); carbon black dust (1333-86-4); ethylenediamine (107-15-3); formaldehyde (gas, dust) (50-00-0); hexamethylene-tetramine (100-97-0); methyl isocyanate [MIC] (624-83-9); naphthylene diisocyanate (3173-72-6); polymethylene polyphenyl isocyanate (9016-87-9); $\mathrm{N}$-methylmorpholine (09-02-4); ozone (gassings) (10028-15-6); paraquat (4685-14-7); diammonium peroxodisulfate (7727-54-0); phenylglycine acid chloride (39478-47-2); piperazine dihydrochloride (142-64-3); polyvinyl chloride (fume) (9002-86-2); rosin core solder; thermal decomposition (8050-09-7); vanadium (7440-62-2) + divanadium pentoxide (1314-62-1); cleaning agents (not specified); green coffee [78]; diesel exhaust; endotoxin; oil (spill); paint (fumes); pesticides (unspecified); reactive dyes; refractory ceramic fibers [RCF]; smoke (fires, pyrolysis products; oil fire and dust storm); soldering flux; solvents (unspecified); healthcare workers; poultry confinement; slaughter house; metal industry workers

Nitrogen chloride (10025-85-1): polyamines; aliphatic; potassium persulfate (7727-21-1) and ammonium peroxydisulfate (7727-54-0); grain rice [78]

Acids not specified; hydrochloric acids (7647-01-0); alkyl cyanoacrylates; 3-amino-5-mercapto-1;2,4-triazole I(16691-43-3); aziridine, polyfunctional [78] (64265-57-2); chloramine T (powder dust) (7080-50-4); chromate (not specified) 3-(diamino-amino)propylamine (109-55-7); dichlorodiethyl sulfide (505-60-2); 2-diethylaminoethanol (100-37-8); diinitrogen tetraoxide (10544-72-6);

hexamethylene diisocyanate [HDI], plus isodurane diisocyanate (822-06-0);

HDI biuret plus (4035-89-6); anhydrous nickel sulfate (7786-81-4); hexahydrate (10101-97-0); paraphenylenediamine (106-50-3); persulfate (not specified):

polypropylene, heated to $250^{\circ} \mathrm{C}$ (9003-07-0); potassium dichromate (7778-50-9); 
Table 3 Strength of evidence for occupational asthma-caused by allergens, irritants or worksites according to the modified RCGP three-star system (Continued)

potassium aluminum tetrafluoride (14484-69-6); sodium iso-nonanoyl oxybenzene sulfonate [SINOS] (123354-92-7): sodium metabisulfite (7681-57-4); styrene monomer (100-42-5); chloroluorocarbons (degradation pron

hairdressing chemicals; lubricants (unspecified): paper dust A111; iliphatic

polyamines; polyester; powder paints; smoke (biomass, indoor)

$275 / 94$

Unlisted as no corroborating scientific evidence presented

Unlisted as no corroborating scientific evidence presented

CAS, Chemical abstracts service.

$R C G P$, Royal College of General Practitioners. 
Table 436 agents identified as occupational asthma-inducing allergens as well as irritants (see column 1 of Table 3 for full range of evidence levels)

\begin{tabular}{|c|c|c|c|c|}
\hline Agent & Evidence level as allergen & Evidence level as irritant & H334 & H335 \\
\hline Aluminium/potroom & - & * & & \\
\hline 2-Ethanolamine & - & - & & $x$ \\
\hline Aminoethylethanolamine & - & - & & $x$ \\
\hline Anhydrides, various & - & * & $x$ & \\
\hline Anhydrides, hexahydrophthalic & * & - & $x$ & \\
\hline Anhydrides, maleic & - & - & $x$ & \\
\hline Anhydrides, methyltetrahydrophththalic & - & - & $x$ & \\
\hline Anhydrides, phthalic anhydride & ${ }^{*}\left[{ }^{*}\right]$ & ${ }^{*}\left[{ }^{*}\right]$ & $x$ & $x$ \\
\hline Anhydrides, tetrachlorophthalic anhydride & $(*)$ & * & $x$ & \\
\hline Azobisformamide & - & * & $x$ & \\
\hline Captafol & - & - & & \\
\hline Chloramine $T$ & $(*)$ & $(*)$ & $x$ & \\
\hline Chlorohexidine & - & - & $x$ & $x$ \\
\hline Cobalt & - & ** & & \\
\hline Diethanolamine & - & - & & \\
\hline Formaldehyde & - & * & & $x$ \\
\hline Glutaraldehyde & - & ${ }^{*}\left[{ }^{*}\right]$ & $x$ & \\
\hline Hexachlorphene & - & - & & \\
\hline Isocyanate, diphenylmethane diisocyanate (MDI) & $*^{*}\left[{ }^{*}\right]$ & ** & $x$ & $x$ \\
\hline Isocyanate, hexamethylene diisocyanate (HDI) & * & $(*)$ & $x$ & $x$ \\
\hline Isocyanate, 1,5-naphthylene diisocyanate (NDI) & - & $(*)$ & $x$ & $x$ \\
\hline Isocyanate, toluene diisocyanate (TDI) & ** & $* *$ & $x$ & $x$ \\
\hline Isocyanate, triglycidil isocyanurate & - & - & & \\
\hline Paraphenylenediamine & - & $(*)$ & & \\
\hline Persulfate & * & $(*)$ & $x$ & $x$ \\
\hline Piperazine dihydrochloride & - & * & $x$ & \\
\hline Platinum salts & $* *$ & $* *$ & & \\
\hline Tetrachloroisophthalonitrile & - & - & & $x$ \\
\hline Tributyl tin oxide & - & - & & \\
\hline Vanadium & - & * & & \\
\hline Zinc & - & - & & \\
\hline Green coffee (dust) & $*^{*}\left[{ }^{*}\right]$ & * & & \\
\hline Reactive dye & $* *$ & * & & \\
\hline Welding fumes & - & $* *$ & & \\
\hline Farming & $* *$ & ${ }^{*}\left[{ }^{*}\right]$ & & \\
\hline Poultry confinement & {$\left[{ }^{*}\right]$} & $*(*)$ & & \\
\hline
\end{tabular}

A continuously updated classification of allergenic or irritant occupational asthma agents has been provided by the American Conference of Governmental Industrial Hygienists (ACGIH) [29], the German MAK commission [30], the Health and Safety Executive [31] and the European Community [14]. At present, the new international labelling of working materials hazardous to health (GHS; EU: CLP), which includes airway allergenic and iritative agents, has been put in force and has replaced the hitherto $\mathrm{R}$ and $\mathrm{S}$ notes with hazard $(\mathrm{H})$ and precautionary statements $(\mathrm{P})$ as well as by new hazard pictograms (European Parliament [14], United Nations [32]).

These reviews and classifications all lack an evidencebased evaluation of identified agents in the clinical literature. An evidence-based evaluation of the literature is of particular importance for case management and 
diagnostics in clinical practice. Thus, the objective of this work was to provide a scientific compendium of practical relevance, exhaustively listing the agents and worksites known to cause occupational asthma.

From more than 3,000 publications, 1,339 were retrieved from our Medline/PubMed and additional database searches, which refer to 372 individual agents or worksites that have been identified to cause allergic occupational asthma and 184 individual agents or worksites known to cause irritant occupational asthma. Of these 520 individual agents or worksites, 36 occurred in more than one category.

Evidence for causing occupational asthma was found for 78 allergens and for 71 irritants, respectively, with 8 eliciting an allergic as well as an irritative pathomechanism, establishing 141 in total.

The evidence levels for causing occupational asthma of many of the listed agents or worksites are moderate to low since only about a quarter of the identified studies were analytical, primarily because randomised controlled trials are not considered ethical when studying the exposure effects of harmful agents. Therefore, high quality studies are largely absent and the few available studies are frequently small in number of workers studied.

The vast majority are surveys, case series or case reports with evidence levels rated very low. The common diagnostic procedure for occupational asthma in clinical settings is a stepwise approach, including questionnaires about asthma-specific symptoms as well as respiratory and allergy assessments. Self-reported work-related symptoms are relatively sensitive indicators in the diagnosis of occupational asthma but the specificity is low. In approximately one third of the included studies, self-reported asthma symptoms or physician-reported asthma were used as the only diagnostic approach. Lung function, allergy testing and the diagnostic gold standards, serial spirometric or peak flow measurements (sPFT) or specific inhalation challenges, were each applied in only about one third to half of studies.

The level of evidence for single agents also depends on the absolute number of publications. Agents for which the research activity is higher may obtain higher levels in our rating system and, conversely, an absence or a low evidence grade of an occupational agent (e.g. in studies without SIC or lung function testing) does not necessarily exclude its potential for causing occupational asthma.

It is evident that more work is needed to consolidate the gaps, such as the study of potential asthma-inducing agents which have not or only rarely been investigated so far. This current overview provides a basis for such supplementary work and for surveillance programs of endangered workers. The latter may facilitate early diagnosis and the application of appropriate secondary preventive measures, leading to a significant reduction of asthma from identified causative exposure in the workplace.

\section{Competing interests}

The author declares that he has no competing interests.

Received: 15 April 2013 Accepted: 14 May 2013

Published: 24 May 2013

\section{References}

1. Bernstein IL, Chan-Yeung M, Malo JL, Bernstein Dl: Asthma in the workplace and related conditions. 3rd edition. New York: Taylor \& Francis; 2006.

2. Baur X, Aasen TB, Burge PS, Heederik D, Henneberger PK, Maestrelli P, Schlunssen V, Vandenplas O, Wilken D: The management of work-related asthma guidelines: a broader perspective. Eur Respir Rev 2012, 21(124):125-139.

3. Baur X, Sigsgaard T, Aasen TB, Burge PS, Heederik D, Henneberger $P$, Maestrelli P, Rooyackers J, Schlunssen V, Vandenplas O, et al: Guidelines for the management of work-related asthma. Eur Respir J 2012, 39(3):529-545.

4. Tarlo SM, Balmes J, Balkissoon R, Beach J, Beckett W, Bernstein D, Blanc PD, Brooks SM, Cowl CT, Daroowalla F, et al: Diagnosis and management of work-related asthma: American College of Chest Physicians Consensus Statement. Chest 2008, 134(Supplement):1S-41S.

5. Baur $X$, Bakehe $P$ : Allergens causing occupational asthma - an evidence-based evaluation of the literature. Int Arch Occ Env Health 2013. [Epub ahead of print] PMID:23595938.

6. Baur X, Bakehe P, Vellguth $\mathrm{H}$ : Bronchial asthma and COPD due to irritants in the workplace - an evidence-based approach. J Occup Med Toxicol 2012, 7(1):19.

7. Meyer JD, Holt DL, Cherry NM, Mcdonald JC: SWORD '98: surveillance of work-related and occupational respiratory disease in the UK. Occup Med (Lond) 1999, 49(8):485-489.

8. Ross DJ, Keynes HL, McDonald JC: SWORD '96: Surveillance of workrelated and occupational respiratory disease in the UK. Occup Med (Lond) 1997, 47(6):377-381.

9. Meyer JD, Holt DL, Chen Y, Cherry NM, McDonald JC: SWORD '99: surveillance of work-related and occupational respiratory disease in the UK. Occup Med (Lond) 2001, 51(3):204-208.

10. Gannon PF, Burge PS, Midland Thoracic Society Research Group: The SHIELD scheme in the West Midlands Region. United Kingdom. $\mathrm{Br} J$ Ind Med 1993, 50(9):791-796.

11. Esterhuizen TM, Hnizdo E, Rees D: Occurrence and causes of occupational asthma in South Africa-results from SORDSA's Occupational Asthma Registry, 1997-1999. S Afr Med J 2001, 91(6):509-513.

12. Buckley $L A$, Jiang $X Z$, James $R A$, Morgan $K T$, Barrow CS: Respiratory tract lesions induced by sensory irritants at the RD50 concentration. Toxicol Appl Pharmacol 1984, 74(3):417-429.

13. Haupt B, Drechsel-Schlund C, Guldner K, Rogosky E, Plinske W, Butz M: Dokumentation des Berufskrankheiten-Geschehens in Deutschland. BK-DOK 2005. Sankt Augustin: Deutsche Gesetzliche Unfallversicherung (DGUV); 2007

14. REGULATION (EC) No 1272/2008 OF THE EUROPEAN PARLIAMENT AND OF THE COUNCIL of 16 December 2008 on classification, labelling and packaging of substances and mixtures, amending and repealing Directives 67/548/EEC and 1999/45/EC, and amending Regulation (EC) No 1907/2006. Luxembourg: The European Parliament and The Council of the European Union; 2008. http://ec.europa.eu/enterprise/sectors/chemicals/documents/classification/\#h2-1.

15. Harbour R, Miller J: A new system for grading recommendations in evidence based guidelines. BMJ 2001, 323(7308):334-336.

16. Nicholson PJ, Cullinan P, Burge PS, Boyle C: Occupational asthma: Prevention, identification \& management: Systematic review \& recommendations. London: British Occupational Health Research Foundation; 2010.

17. Anees W, Gannon PF, Huggins V, Pantin CF, Burge PS: Effect of peak expiratory flow data quantity on diagnostic sensitivity and specificity in occupational asthma. Eur Respir J 2004, 23(5):730-734.

18. Balmes J, Becklake M, Blanc P, Henneberger P, Kreiss K, Mapp C, Milton D, Schwartz D, Toren K, Viegi G: American Thoracic Society Statement: Occupational contribution to the burden of airway disease. Am J Respir Crit Care Med 2003, 167(5):787-797.

19. Kogevinas M, Anto JM, Sunyer J, Tobias A, Kromhout H, Burney P, European Community Respiratory Health Survey Study Group: Occupational asthma in Europe and other industrialised areas: a population-based study. Lancet 1999, 353(9166):1750-1754. 
20. Burge PS, Moore VC, Robertson AS: Sensitization and irritant-induced occupational asthma with latency are clinically indistinguishable. Occup Med (Lond) 2012, 62(2):129-133.

21. van Kampen V, Merget R, Baur X: Occupational airway sensitizers: an overview on the respective literature. Am J Ind Med 2000, 38(2):164-218.

22. Quirce S, Sastre J: New causes of occupational asthma. Curr Opin Allergy Clin Immunol 2011, 11(2):80-85.

23. Mapp CE, Boschetto P, Maestrelli P, Fabbri LM: Occupational asthma. Am J Respir Crit Care Med 2005, 172(3):280-305.

24. Malo JL, Chan-Yeung M: Agents causing occupational asthma. J Allergy Clin Immunol 2009, 123(3):545-550

25. Lombardo L, Balmes JR: Occupational asthma: a review. Environ Health Perspect 2000, 108(Suppl 4):697-704

26. Baur X: Airborne allergens and irritants in the workplace. In Allergy and allergic diseases. Edited by Kay AB, Kaplan AP, Bousquet J, Holt PG. Oxford: Blackwell Publishing; 2008:1017-1122.

27. Bernstein IL, Chan-Yeung M: Asthma in the workplace and related conditions. New York: Taylor \& Francis; 2006.

28. Toren K, Blanc PD: Asthma caused by occupational exposures is common - a systematic analysis of estimates of the population-attributable fraction. BMC Pulm Med 2009, 9:7.

29. ACGIH. American Conference of Governmental Industrial Hygienists A 2009 TLVV $^{\oplus}$ and BEls ${ }^{\oplus}$ Cincinnati. 2009.

30. Hartwig A: The MAK-Collection for Occupational Health and Safety. Part I: MAK Value Documentations. Weinheim, Berlin: Wiley-VCH; 2013.

31. Occupational Asthma. http://www.hse.gov.uk/asthma/asthmagen.pdf.

32. United Nations: Globally Harmonized System of Classification and Labelling of Chemicals (GHS). 3rd edition. Geneva: United Nations; 2009:297-401.

doi:10.1186/1745-6673-8-15

Cite this article as: Baur: A compendium of causative agents of occupational asthma. Journal of Occupational Medicine and Toxicology 2013 8:15.

\section{Submit your next manuscript to BioMed Central and take full advantage of:}

- Convenient online submission

- Thorough peer review

- No space constraints or color figure charges

- Immediate publication on acceptance

- Inclusion in PubMed, CAS, Scopus and Google Scholar

- Research which is freely available for redistribution 